\title{
Influence of Occupational Stress on Organisational Performance
}

\author{
Srđan VULANOVIĆ, Milan DELIĆ, llija ĆOSIĆ, Marina ŽIŽAKOV, Stana VASIĆ
}

\begin{abstract}
The effective occupational health and safety management system is aimed to reduce risks of injuries and occupational ill health in the organisation. The relation between occupational health and safety management and organisational performance has already been researched and established by some researchers. By creating safe and healthy environment, top management invests in optimal business conditions with agile work power that can fully contribute to achieving company goals, but the expected results and achievement of set goals may vary depending on stress-related working climate. The influence of stress factor as mediator between occupational health and safety management and organisational performance was a subject of research that is shown in this paper. A survey concerning constructs related to the topic was carried out in Serbia, and the results of the survey were analysed using structural equation modeling (SEM). The results of the research proved that occupational health and safety management system has a direct impact on employees' stress, and their stress has a significant, mediating, influence on organisational OHS performance.
\end{abstract}

Keywords: occupational health and safety; organisational performance; stress management; work stress

\section{INTRODUCTION (Introductory remarks)}

Occupational health and safety management system (OHSMS) is an integral part of every organisation's management system. It primarily aims to achieve safer working conditions and reduce the number of injuries, occupational diseases and illnesses related to work, but secondarily can influence on overall management system performance [1]. The authors of this paper wanted to point out at a direct relation between the establishment of appropriate conditions for safe operation and creation of productive and creative climate that benefits firm performance.

Some papers also proved that better health and safety performance improves company performance. Highperformance work system is significantly associated with occupational safety [2]. These findings are consistent with [3] which showed that many of the management practices that are frequently applied to improve organisational performance have equal or greater effects on occupational injuries. This paper highlights the significance of the occupational stress as a mediator between OHSMS dimensions and organisational performance and proves that the working stress has a strong impact on overall performance of the organisation. Some authors have already established the relationship between workplace stressors and personal performance of employees [4] but stress management was rarely considered as an integral part of OHSMS, and its influence on OHS performance was never established.

In subsequent text, the research dimensions are defined, research instrument is explained and the obtained results are presented and discussed.

\section{THE RESEARCH MODEL}

The authors of this paper have elaborated significant OHSMS dimensions in detail, and have defined a questionnaire that was used as a research instrument in this study. The questionnaire had 47 manifest variables relating to relevant constructs, and the survey was conducted in 116 companies in Serbia. The research model was empirically tested and was found to be valid and reliable.

\section{DIMENSIONS OF OCCUPATIONAL HEALTH AND SAFETY (OHS)}

Measurement is an accepted part of the "plan-docheck-act" management process [5]. According to the "Deming improvement cycle", global key elements for OHSMS measurement are shown in the following list [6]:

- Policy,

- Organizing,

- Planning and implementation,

- Measuring performance and

- Audit and review.

Many authors have also established numerous factors that have a strong influence on OHSMS in their more recent research $[4,7,8]$. Those factors can be clustered in five groups:

- Leadership,

- Involvement of employees,

- Working environment,

- OHS risk management,

- OHS training and similar.

It can be stated that these factors are harmonized with the requirements of new management standards such as ISO 9001:2015 - Quality Management System (QMS), ISO 14001:2014 - Environmental Management System (EMS), ISO 45001:2018 - Occupational and Health Safety Management System (OHSMS) and alike. According to that, the OHS dimensions in this paper were established as follows:

1. Leadership (LDS)

The scientific community is unanimous regarding the crucial role of leadership in organisations. Without full commitment of top management, there is no effective functioning of any system. The role of managers in practicing leadership is one of the keys of quality management [9-11]. The leadership is also one of the core principles of QMS and should represent one of the crucial dimensions of OHS.

2. Employee involvement (EI)

Participation of the employees in health and safety activities is studied in several references [12]. Employee involvement or Engagement of people is also one of the QMS principles. Daily basis active involvement in the implementation and auditing of the system is one of the 
most important factors [13], so management should ensure a favourable climate for the development and implementation of quality management, involving all employees [14]. Concerning the fact that OHS is mostly aimed at employees and their health and safety [15], it is more than logical to include this factor as a construct of OHS.

3. Work environment (WE)

The working environment is a standard element of OHSMS. It is the place where the work is carried out and includes jobs, working conditions, working procedures and relationships in the work process. According to legal requirements in Serbia, working conditions should be controlled every 3 years, which include: microclimate, chemical harm, physical harm, lighting and biological harm. Work and working conditions have a significant contribution to health disparities [16]. Work-related illnesses are very common, even in offices [17], and employees should influence improvement of workplace health and safety through worker representation [18].

4. Training (TRN)

OHS training for employees and contractors is one of the most important practices in effective OHSMS. According to legal requirements in Serbia, the OHS training for all employees must be carried out every 4 years, and the workers employed in high risk work places are obliged to undergo the training every single year. It is established that Exposure to low levels of safety practices and job tasks that interfere with ability to comply with safety practices, significantly increased the likelihood of having a work injury-related absence [19].

Some scientific studies highlighted a strong support for the effectiveness of training on worker OHS attitudes and beliefs [20]. It is also observed that participation in training activities exerted great impact because the training method had the learners more involved [21].

5. Risk management (RM)

Managing risks in an integrated way with the organisation's operations has become increasingly important in recent years, since it not only cuts accident rates but can also improve the firm's productivity and economic and financial results [22]. Thus, preventing occupational risks is an essential element in business management, with important strategic implications for the organisation [23] and [6]. That is why the risk management is one of the most complex OHS elements.

The overall goal of every effective OHSMS is to eliminate or reduce health and safety risks. Consequences of identified risks may vary from mild incidents to emergency situations, but all of them must be assessed and adequately treated. That is why the authors of this paper established second order constructs to describe risk management, as follows:

- Incidents (INC),

- Emergency situations (ES) and

- Risk assessment and measures (RAM).

6. Stress management (SM)

It is now generally acknowledged that stress is the product of an imbalance between appraisals of environmental demands and individual resources [24, 25]. Work-related stress is one of the major concerns for occupational safety and health, and it has been estimated that about half of all work absences is due to work-related stress disorders $[17,26]$. Stress can even influence the progress of management standard implementation [27]. The causes of stress at work were perceived as being predominantly organisational, but the impact of stress on the employee was more salient than organisational outcomes [28]. It has also been established that combined workplace stressors have strong relationship with mood, physiology, and performance of the employee [29, 30].

Considering mentioned theoretical inputs, the authors of this paper created slightly different approach in measuring the functioning of OHSMS, by introducing the occupational stress as a dimension. The questionnaire related to this dimension was developed according to similar researches [31-33].

7. Occupational health and safety performance (OHSP)

Measuring performance is as much part of a health and safety management system as financial, production or service delivery management. According to [6] the easiest way for measuring OHSMS performance is a reactive monitoring of:

- Injuries and work-related ill health,

- Other losses such as damage to property,

- Incidents, including those with the potential to cause injury, ill health or loss,

- Hazards and faults and

- Weaknesses or omissions in performance standards and systems.

Listed items are also subject of monitoring by legal requirements.

Some authors like [1] have demonstrated a positive effect of occupational safety management on overall company's performance such as competiveness and economic-financial performance. In measuring OHSP, they proposed a model consisting of the following dimensions:

- Personal injuries,

- Material damage,

- Training,

- Employees motivation and

- Absenteeism/lost time.

Mentioned researches were used in this paper, when variables that define occupational health and safety performance were established.

\section{RELATIONSHIP BETWEEN RESEARCH DIMENSIONS}

Occupational health and safety was recognized to be a complex, multidimensional concept encompassing many attributes and many predetermining factors $[4,8]$. On the other hand, many researchers have studied and evaluated dimensions of Occupational health and safety performance $[1,7,34]$. These findings, along with researches on stress management, concerning work-related stress [25] and health-specific leadership [35] represent theoretical backgrounds that support the following hypotheses:

H1: Occupational health and safety (OHS) is positively related to occupational health and safety performance (OHSP).

H2: Occupational health and safety (OHS) is positively related to stress management (SM).

H3: Stress management (SM) is positively related to occupational health and safety performance (OHSP). 
The hypothesized model resulted with conceptual framework of 3 first order constructs (OHS, SM \& OHSP), where only the OHS construct was consisted of 5 second order constructs, which is shown in Fig. 1.

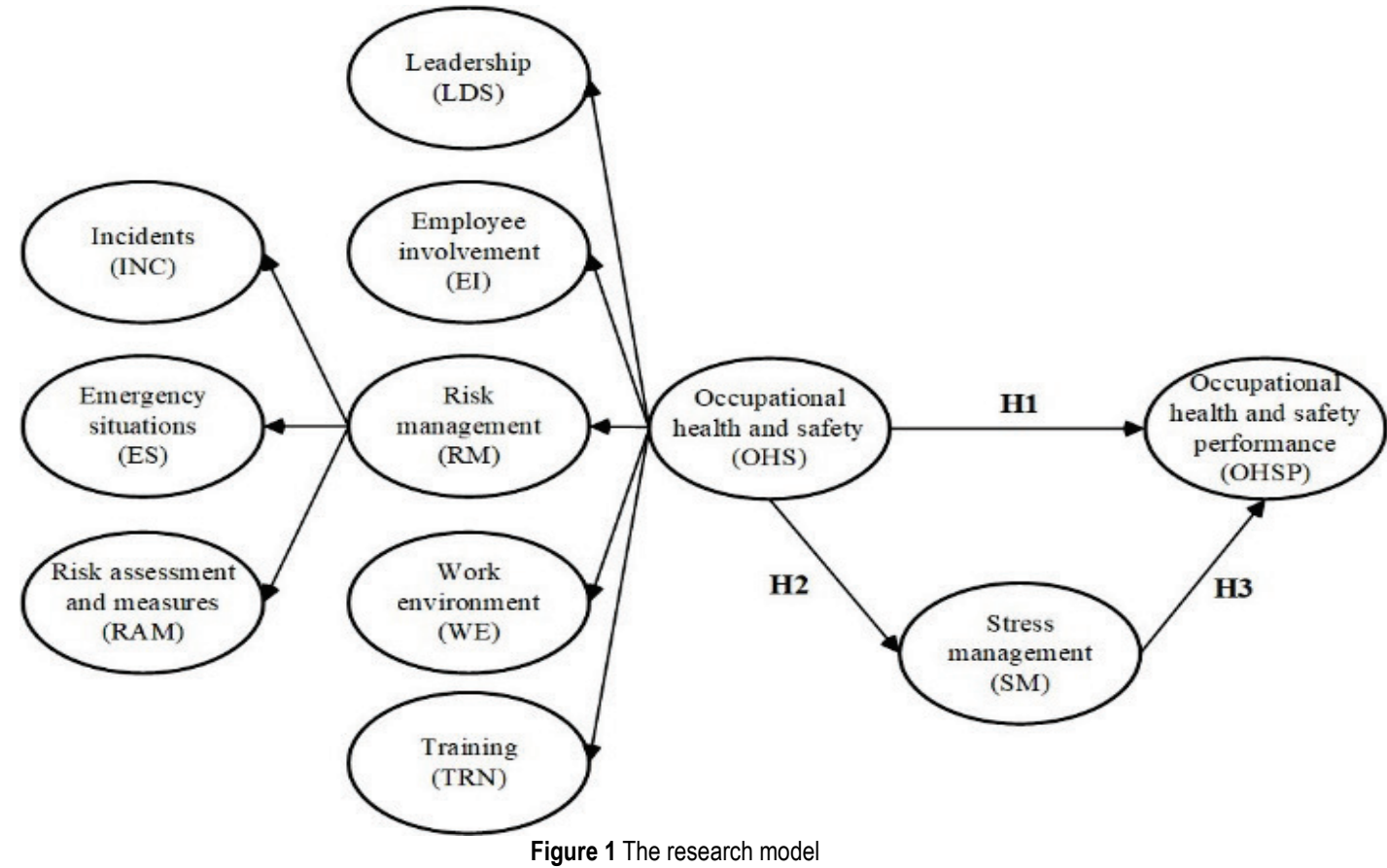

\section{RESEARCH METHOD}

\subsection{Measures and Questionnaire Development}

For the purpose of this research, the original questionnaire was developed and structured in 8 sections. In the first section respondents gave background information about themselves and their organisation. In the next 5 sections, the construct of OHS was operationalized with a total of 36 manifest variables. According to the relevant literature sources, Occupational health and safety was operationalized with:

1. Leadership (6 manifest variables),

2. Employee involvement (5 manifest variables),

3. Work environment (6 manifest variables),

4. Training (5 manifest variables) and

5. Risk management (14 manifest variables).

The Risk management itself, as a second order construct, was composed of:

1. Incidents (5 manifest variables),

2. Emergency situations (4 manifest variables) and

3. Risk assessment and measures (5 manifest variables).

In the seventh and eight sections two more constructs were added:

1. Stress management (5 manifest variables) and

2. Occupational health and safety performance (6 manifest variables).

All statements used as manifest variables for listed constructs, were affirmative. To capture the respondents subjective estimates about the statements, a five point unipolar Likert type scale was used [36]. In the scale the far left point (i.e. 1) is a measure of strong disagreement with the statement, and the far right (i.e. 5) is a measure of full agreement with the statement. The middle section of the scale (i.e. 3) is an indicator of half consent with the statement.

For the purpose of conducting face validity, final version of the questionnaire was tested with the group of associates and University professors dealing with the occupational health and safety. After the face validity, no major complaints regarding the length and clarity of the questionnaire were registered, so the phase of data collection could be started.

\subsection{Data Collection and Sample}

Unfortunately, there are no precise statistics on the use of OHSAS 18001, alias ISO 45001 in the world or in Serbia. Concerning the lack of reliable data, the authors of this paper could only assume that the number of OHSAS 18001/ISO 45001 certified companies in Serbia is close to the number of ISO 14001 certified organisations. This approximation was done concerning the fact that OHSAS $18001 /$ ISO 45001 standard is almost word-for-word identical to the ISO 14001 standard, excluding the specific terminology used in each standard, and they have always had the same structure. Besides that, the authors of this paper have a lot of experience with consulting services in Serbia and region, concerning the implementation of management standards requirements, and according to their knowledge, prevalent number of organisations aim for the integrated implementation of both standards. According to [37] the number of ISO 14001 certified companies in Serbia in the year of 2017 was 887, and it is assumed that the number of OHSAS 18001/ISO 45001 certified companies in Serbia is similar. The questionnaire was distributed electronically or manually to 446 companies (just over $50 \%$ of the assessed number of existing certified organisations situated in Serbia). After the 3 months period, responses were obtained from 166 respondents. However, only 116 correctly filled questionnaires were taken into consideration and analysed, leading to a total of $26 \%$ response rate. 


\subsection{Sample Demographics}

The sample consisted of 116 safety officers (i.e. organisations). Most of them were males (74, 63.8\%), followed by the less frequent female respondents (42, $36.2 \%$ ). Further, all types of age groups were included into study design. Consequently, $18(15.5 \%)$ respondents were below the age of $30,32(27.6 \%)$ of them were between the age of 31 and 40, $41(35.3 \%)$ respondents fell into the age category between 41 and 50, while $21(18.1 \%)$ respondents were older than 51 . Only a small fraction of respondents failed to provide this data $(4,3.4 \%)$. Roughly, equal number of respondents comes from production $(36,31 \%)$, service $(46,39.7 \%)$ and production/service $(34,29.3 \%)$ types of organisations. Similarly, the number of large (39, $33.6 \%)$, medium $(29,25 \%)$, small $(23,19.8 \%)$ and micro $(24,20.7 \%)$ organisations were roughly equally included into the sample, with only a small number of missing data $(1,0.9 \%)$. Out of 116 respondents, most come from the industrial sector, followed by the mining and energetics (Tab. 1).

Table 1 Sample demographics by industry sectors

\begin{tabular}{|l|c|c|}
\hline \multicolumn{1}{|c|}{ Sector } & $N$ & $\%$ \\
\hline Industrials & 61 & 52.6 \\
\hline Agriculture & 1 & 0.9 \\
\hline Mining and energetics & 10 & 8.6 \\
\hline Traffic and transport & 9 & 7.8 \\
\hline Public utilities & 9 & 7.8 \\
\hline Trade and commerce & 9 & 7.8 \\
\hline Tourism & 2 & 1.7 \\
\hline Chemicals and pharmacy & 3 & 2.6 \\
\hline Insurance & 2 & 1.7 \\
\hline Education & 3 & 2.6 \\
\hline Culture and sport & 1 & 0.9 \\
\hline IT & 1 & 0.9 \\
\hline Healthcare & 5 & 4.3 \\
\hline Total & 116 & 100.0 \\
\hline
\end{tabular}

Further, besides aforementioned sample demographics, respondents were given an option to provide some specifics regarding their OHS (Tab. 2).

Table 2 Specifics about OHS system

\begin{tabular}{|l|c|c|c|}
\hline \multicolumn{1}{|c|}{ OHS system specific questions } & Yes & No & Missing \\
\hline $\begin{array}{l}\text { Does your organization have workplaces with } \\
\text { increased risk of injury? }\end{array}$ & 86 & 30 & - \\
\hline $\begin{array}{l}\text { Does your organization have a tendency to } \\
\text { sanction workers, if safety measures are } \\
\text { overlooked and not followed? }\end{array}$ & 79 & 36 & 1 \\
\hline $\begin{array}{l}\text { Does your organization motivate and reward } \\
\text { employees towards the continuous } \\
\text { development of OHS system? }\end{array}$ & 53 & 62 & 1 \\
\hline
\end{tabular}

By looking into these answers, it could be said that most of the respondents are dealing with some type of stress, whether it comes from increased risk of injury, formal system sanctions or the lack of employee motivation towards the development of OHS. Moreover, such responses provide rationale towards the inclusion of $\mathrm{SM}$, as an integral part of OHS, which, mostly, was not the case in previous studies and practitioners in various industry sectors.

\section{DATA ANALYSIS}

In contrast to the covariance structural analysis approach (CBSEM), which is dominant in the field of management science [38], this study was based on variance-based method (PLS).

Mainly, the first reason is sample size, which is, by the rule of thumb, too small for CBSEM, [39]. Also, rather than to test structural integrity and consistency of latent variables (confirmatory approach, [39]), this study is more concerned with the predictive power of stress management, with respect to occupational health and safety and its performance (explanatory approach, [39]). Thus, the focus is on structural analysis and the explanation of relationships between these dimensions, without getting into details about the constitution of higher-order constructs by its sub-elements. Finally, speaking in the context of research population, to the best of our knowledge, similar studies in the field are mostly anectodical by nature, seriously lacking in statistical power to empirically underpin the constitution of research constructs. Bearing in mind aforementioned, to "reproduce" the research model in the context of research population, is a doubtful approach; and explanatory route in structural modeling was more convenient for this study. Given that OHS is a multidimensional, higher-order construct, to test the quality of relationships between manifest variables and their respectful latent factors, repeated indicators approach (poor man's approach) was used, which is the most popular method of estimating higher order constructs in PLS-SEM [40]. At first, the outer model was tested on reliability and validity. Then, the structural model assessment of the inner model was carried out [40] and [39]. Afterwards, significance of relationships between latent factors was analysed and discussed.

\subsection{Measurement Model Assessment (Outer Model Reliability and Validity)}

The extent of latent variable reflectiveness (reflective approach, [39, 40]) by their respectful indicators was assessed through unidimensionality tests. Thus, values of Cronbach's alpha $(\alpha)$, Dillon-Goldstein's rho $(D G)$ and eigenvalues indicators' correlation matrix (eig. 1st and eig. 2nd) were analysed [40]. According to literature sources, Cronbach's alpha should be, at least, 0.7 [36]. All constructs met this criterion. Further, as a rule of thumb, a construct is considered to be unidimensional, if the value for Dillon-Goldstein's rho is above 0.7 [40], which was the case for all constructs. Last but not the least, if a construct is unidimensional, the first eigenvalue should be larger than one, whereas the second one should be smaller than one [40]. For constructs OHS and OHSP, the latter criterion was not met (OHS's eig. $2^{\text {nd }}=2.137$, OHSP's eig. $\left.2^{\text {nd }}=1.170\right)$. Specifically, within higher-order, OHS construct, seven manifest variables had outer-loadings below $0.67(\geq 0.7,[39,40])$. Although this value was acceptable within their respectful, lower-order constructs (EI, TRN, INC, ES and RAM); nevertheless, they were omitted from the research model. Speaking in the context of OHSP, values for outer-loadings were acceptable for all manifest variables. In addition, their cross-loadings with OHS were much lower. Therefore, they were retained. 
Finally, average variance extracted (AVE, [39]) and goodness-of-fit were examined (GOF, [40]). AVE value was at least at 0.5 , for each construct [39], while the GOF for the research model was above the recommended value of 0.7 . Results of reliability and validity of test are shown in Tab. 3 .

Table 3 Unidimensionality results

\begin{tabular}{|c|c|c|c|c|c|c|c|c|}
\hline Cons. & Higher order cons. & $M V \mathrm{~s}$ & $O M V_{\mathrm{S}}$ & $\alpha$ & $D G$ & eig. $1^{\text {st }}$ & eig. $2^{\text {nd }}$ & $A V E$ \\
\hline OHS & LDS, EI, WE, TRN, RM & 29 & 7 & 0.96 & 0.98 & 17.15 & 1.58 & 0.59 \\
\hline LDS & - & 6 & - & 0.94 & 0.95 & 4.54 & 0.56 & 0.76 \\
\hline EI & - & 3 & 2 & 0.83 & 0.90 & 2.23 & 0.41 & 0.74 \\
\hline WE & - & 6 & - & 0.89 & 0.97 & 3.87 & 0.70 & 0.64 \\
\hline TRN & - & 4 & 1 & 0.90 & 0.93 & 3.12 & 0.44 & 0.78 \\
\hline $\mathrm{RM}$ & INC, ES, RAM & 10 & 4 & 0.95 & 0.95 & 6.72 & 0.85 & 0.67 \\
\hline INC & - & 4 & 1 & 0.88 & 0.92 & 2.94 & 0.55 & 0.74 \\
\hline ES & - & 2 & 2 & 0.88 & 0.94 & 1.79 & 0.22 & 0.89 \\
\hline RAM & - & 4 & 1 & 0.98 & 0.94 & 3.20 & 0.32 & 0.80 \\
\hline OHSP & - & 6 & - & 0.92 & 0.94 & 4.24 & 1.17 & 0.71 \\
\hline SM & - & 5 & - & 0.88 & 0.91 & 3.37 & 0.70 & 0.67 \\
\hline
\end{tabular}

Cons. - construct abbreviation, higher order cons. - inclusion of lower-order constructs within higher-order, $M V \mathrm{~s}$ - manifest variables per construct, $O M V \mathrm{~s}$ - number of omitted manifest variables, $A V E$ - average variance extracted

\subsection{Structural Model Assessment (Inner Model)}

The coefficient of determination $\left(R^{2}\right)$ for SM had a moderate and acceptable value of $0.41[39,40]$. Further, with SM included, $R^{2}$ coefficient for OHSP had a moderate value, $R^{2}=0.64$, while without, this value was dropped to 0.60 , which is also considered to be moderate and acceptable. Without SM, the impact of OHS on OHSP is strong and statistically significant. With the inclusion of SM, statistical significance of the relationship between OHS and OHSP drops, however, it remains strong. Given that the relationship between OHS and SM, as well as between the SM and OHSP is also strong and statistically significant, it could be argued that SM plays, significant, mediating role between OHS and OHSP. Therefore, it could be argued that all three hypotheses are supported by study results. This is shown in Tab. 4 , while, empirically validated model is given in Fig. 2.

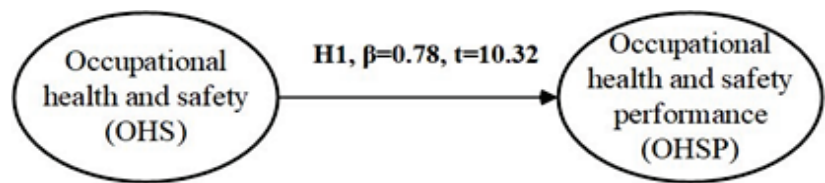

Direct effect of OHS on OHSP without SM

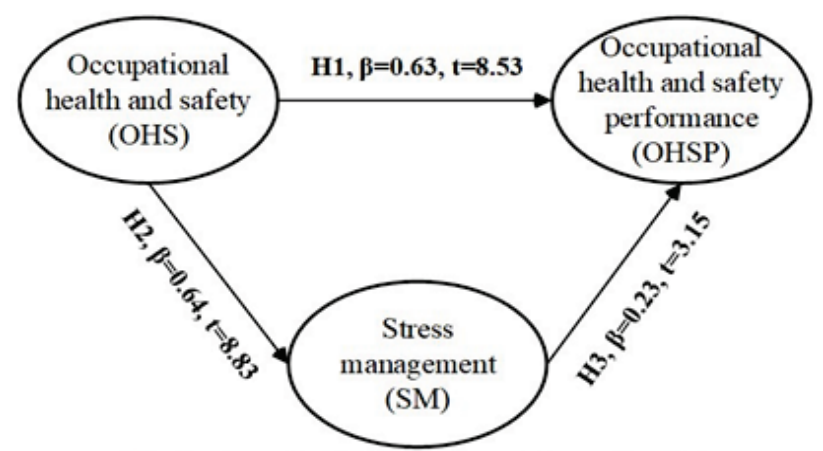

Mediating role of SM between OHS and OHSP Figure 2 Empirically validated model

Table 4 Structural model

\begin{tabular}{|c|c|c|c|c|c|c|c|c|}
\hline Hypothesis & Path & $\beta^{*}$ & $\beta^{* *}$ & $t^{*}$ & $t^{* *}$ & $p^{*}$ & $p^{* *}$ & Supported? \\
\hline$H 1$ & OHS $\rightarrow$ OHSP & 0.63 & 0.78 & 8.53 & 10.32 & 0.000 & 0.000 \\
\hline$H 2$ & OHS $\rightarrow$ SM & 0.64 & - & 8.83 & - & 0.000 & - \\
\hline$H 3$ & SM $\rightarrow$ OHSP & 0.23 & - & 3.15 & - & 0.002 & - \\
\hline
\end{tabular}

*with SM construct included into the research model, **without SM construct, $\beta$ - path coefficient

\section{DISCUSSION}

From the empirically validated model (shown in Fig. 2 ) it can be seen that the direct impact of OHS to OHSP is strong and statistically significant. This is also in line with the findings of researches $[1,7,34]$. According to these findings, hypothesis $H 1$ - Occupational health and safety (OHS) is positively related to occupational health and safety performance (OHSP) has been confirmed.

The relationship between OHS and SM was proved to be even slightly stronger, which was also expected, because many researchers have established great influence of working conditions and organisation culture on work stress [41-42] and similar. Some authors [43] have established that stressor exposure increased OHS risk and work absence. The survey in this research proved those findings in transitional Serbian economy and confirmed hypothesis $H 2$ - Occupational health and safety (OHS) is positively related to stress management (SM).

Regardless of the established importance of SM in OHS and its influence on OHSP, scientific community has not researched direct impact of SM on OHSP. That was the innovative segment of this research, and when Stress management (SM) was introduced as a mediator between OHS and OHSP, it was established that strength of their relationship slightly weakens, but still remains statistically significant. The survey has also established that direct impact of SM on OHSP is statistically significant. In this way, the hypothesis H3 - Stress management (SM) is positively related to occupational health and safety performance (OHSP) should be confirmed. 


\section{CONCLUSION}

The objective of this study was to explore the influence of occupational health and safety management system on employees' stress, and to establish the relationship between stress management and occupational health and safety performance. Relying on existing literature, the authors developed and tested the conceptual framework that explores the new ground in this field. The results from this study indicate that there is statistical significance of the relationship between all three constructs that were analysed (OHS, SM and OHSP).

The belief that stress, and in particular, work stress, is a causal agent in physical and mental disorders as well as organisational outcomes such as absenteeism and reduced productivity has gained widespread acceptance [44]. Only a worker who is not exposed to excessive stress over a long period of time can retain psycho-physical health and provide optimal work performance. The authors consider that work stress is one of the primary causes of increased number of accidents, and in this paper it has been shown that it is closely related to occupational health and safety and also has a significant impact on the OHS performance of the organisation.

\section{REFERENCES}

[1] Fernández-Muñiz, B., Montes-Peón, J. M., \& VázquezOrdás, C. J. (2009). Relation between occupational safety management and firm performance. Safety Science, 47(7), 980 -991. https://doi.org/10.1016/j.ssci.2008.10.022

[2] Zacharatos, A., Barling, J., \& Iverson, R. D. (2005). HighPerformance Work Systems and Occupational Safety. Journal of Applied Psychology, 90(1), 77-93. https://doi.org/10.1037/0021-9010.90.1.77

[3] Kaminski, M. (2001). Unintended consequences: Organizational practices and their impact on workplace safety and productivity. Journal of Occupational Health Psychology, 6(2), $127-138$. https://doi.org/10.1037/1076-8998.6.2.127

[4] Cadieux, J., Roy, M., \& Desmarais, L. (2006). A preliminary validation of a new measure of occupational health and safety. Journal of Safety Research, 37(4), 413-419. https://doi.org/10.1016/j.jsr.2006.04.008

[5] Health Quality Ontario (2013). Measure-ment for Quality Improvement. Primers in Quality Improvement, 1-18. Retrieved from: http://www.hqontario.ca/Portals/0/ Documents/qi/qi-measurement-primer-en.pdf

[6] HSE (2001). A Guide to Measuring Health \& Safety, 1-30. Retrieved from: http://www.hse.gov.uk/opsunit/ perfmeas.pdf

[7] Sinelnikov, S., Inouye, J., \& Kerper, S. (2015). Using leading indicators to measure occupational health and safety performan-ce. Safety Science, 72, 240-248. https://doi.org/10.1016/.jssci.2014.09.010

[8] Podgórski, D. (2015). Measuring operational performance of OSH management system - A demonstration of AHP-based selection of leading key performance indicators. Safety Science, 73, 146 -166. https://doi.org/10.1016/j.ssci.2014.11.018

[9] Sanjay, L., Ahire, Damodar, Y., \& Golhar, M. A. W. (1996). Development and Validation of Tqm Constructs. Decision sciences journal, 27(1), 2004. https://doi.org/10.1111/j.1540-5915.1996.tb00842.x

[10] Tarí, J. J., Molina, J. F., \& Castejón, J. L. (2007). The relationship between quality management practices and their effects on quality outcomes. European Journal of Operational Research, 183(2), 483-501. https://doi.org/10.1016/j.ejor.2006.10.016

[11] Pečujlija, M. et al. (2011). Leadership and productivity in transition: Employees' view in Serbia. Journal of East European Management Studies, 16(3), 251-263. https://doi.org/10.5771/0949-6181-2011-3-251

[12] Hasle, P. \& Limborg, H. J. (2006). A Review of the Literature on Preventive Occupational Health and Safety Activities in Small Enterprises. Industrial Health, 44(1), 612. https://doi.org/10.2486/indhealth.44.6

[13] Tunjic, D., Kljajin, M., \& Kondic, V. (2014). Research and ranking of the factors of impact on efficiency and effectiveness of the quality management system certification process using the prior factor ranking method. Tehnicki Vjesnik, 21(2), 383-388.

[14] Delić, M. et al. (2014). Examining relationships between quality management and organisational performance in transitional economies. Total Quality Management and Business Excellence, 25(3-4), 367-382. https://doi.org/10.1080/14783363.2013.799331

[15] Huang, Y. H. et al. (2006). Safety climate and self-reported injury: Assessing the mediating role of employee safety control. Accident Analysis and Prevention, 38(3), 425-433. https://doi.org/10.1016/j.aap.2005.07.002

[16] Burgard, S. A. \& Lin, K. Y. (2013). Bad Jobs, Bad Health? How Work and Working Conditions Contribute to Health Disparities. American Behavioral Scientist, 57(8), 11051127. https://doi.org/10.1177/0002764213487347

[17] Hedge, A. et al. (1989). Work-related illness in offices: A proposed model of the "sick building syndrome". Environment International, 15(1-6), 143-158. https://doi.org/10.1016/0160-4120(89)90020-2

[18] Walters David, N. T. (2007). Worker Representation and Workplace Health and Safety. Palgrave Macmillan, London. https://doi.org/10.1057/9780230210714

[19] Gimeno, D. et al. (2007). Association of occupation and safety practices with work-injury absence among public hospital employees in Latin America: A study from Costa Rica. Injury Prevention, 13(4), 264-269. https://doi.org/10.1136/ip.2007.015446

[20] Ricci, F. et al. (2016). Effectiveness of occupational health and safety training: A systematic review with meta-analysis. Journal of Workplace Learning, 28(6), 355-377. https://doi.org/10.1108/JWL-11-2015-0087

[21] Burke, M. J. et al. (2006). Relative effectiveness of worker safety and health training methods. American Journal of Public Health, 96(2), 315-324. https://doi.org/10.2105/AJPH.2004.059840

[22] O'Toole, M. (2002). The relationship between employees' perceptions of safety and organizational culture. Journal of safety research, 33(2), 231-243. https://doi.org/10.1016/S0022-4375(02)00014-2

[23] Rikhardsson, P. M. \& Impgaard, M. (2004). Corporate cost of occupational accidents: An activity-based analysis. Accident Analysis and Prevention, 36(2), 173-182. https://doi.org/10.1016/S0001-4575(02)00147-1

[24] Lazarus, R. S. \& Folkman, S. (1984). Stress, Appraisal, and Coping. New York: Springer.

[25] Cousins, R. et al. (2004). "Management Standards" and work-related stress in the UK: Practical development. Work and Stress, 18(2), 113-136. https://doi.org/10.1080/02678370410001734322

[26] Marcatto, F. et al. (2016). Work-related stress risk factors and health outcomes in public sector employees. Safety Science, 89, 274-278. https://doi.org/10.1016/j.ssci.2016.07.003

[27] Mellor, N. et al. (2011). "Management Standards" and workrelated stress in Great Britain: Progress on their implementation. Safety Science, 49(7), 1040-1046. https://doi.org/10.1016/j.ssci.2011.01.010 
[28] Kinman, G. \& Jones, F. (2005). Lay representations of workplace stress: What do people really mean when they say they are stressed? Work and Stress, 19(2), 101-120. https://doi.org/10.1080/02678370500144831

[29] Wellens, B. T. \& Smith, A. P. (2006). Combined workplace stressors and their relationship with mood, physiology, and performance. Work and Stress, 20(3), 245-258. https://doi.org/10.1080/02678370601022712

[30] Glasscock, D. J. et al. (2006). Psychosocial factors and safety behaviour as predictors of accidental work injuries in farming. Work and Stress, 20(2), 173-189. https://doi.org/10.1080/02678370600879724

[31] Edwards, J. A. et al. (2008). Psychometric analysis of the UK Health and Safety Executive's Management Standards workrelated stress Indicator Tool. Work and Stress, 22(2), 96-107. https://doi.org/10.1080/02678370802166599

[32] Searle, B. J., Bright, J. E. H., \& Bochner, S. (1999). Testing the 3 -factor model of occupational stress: The impact of demands, control and social support on a mail sorting task. Work and Stress, 13(3), 268-279. https://doi.org/10.1080/026783799296066

[33] Randall, R., Nielsen, K., \& Tvedt, S. D. (2009). The development of five scales to measure employees' appraisals of organizational-level stress management interventions. Work and Stress, 23(1), 1-23. https://doi.org/10.1080/02678370902815277

[34] Tremblay, A. \& Badri, A. (2018). Assessment of occupational health and safety performance evaluation tools: State of the art and challenges for small and medium-sized enterprises. Safety Science, 101(August 2017), 260-267. https://doi.org/10.1016/j.ssci.2017.09.016

[35] Gurt, J., Schwennen, C., \& Elke, G. (2011). Health-specific leadership: Is there an association between leader consideration for the health of employees and their strain? https://doi.org/10.1080/02678373.2011.595947

[36] Nunnally, J. \& Bernstein, H. (1994). Psychometric theory. New York: McGraw-Hill Inc.

[37] ISO Survey of certifications to management system standards. Retrieved from: https://isotc.iso.org/livelink/livelink? func $=11 \&$ objId $=18808772 \&$ objAction=br owse\&viewType=1 (Accessed: 28 May 2019).

[38] Sarstedt, M., Hair J. F. J. et al. (2016). Estimation issues with PLS and CBSEM: Where the bias lies!. Journal of Business Research, 69, 3998-4010. https://doi.org/10.1016/j.jbusres.2016.06.007

[39] Hair, J. F. J., Hult, G. T. M., Ringle, C., \& Sarstedt, M. (2014). A Primer on Partial Least Squares Structural Equation Modeling (PLS-SEM). USA: SAGE.

[40] Sánchez, G. (2013). PLS Path Modeling with R, Gaston Sanchez. Retrieved from: http://gastonsanchez.com/ PLS_Path_Modeling_with_R.pdf.

[41] Mikkelsen, A., Saksvik, P. Q., Eriksen, H. R., \& Ursin, H. (1999). The impact of learning opportunities and decision authority on occupational health. Work and Stress, 13(1), 2031. https://doi.org/10.1080/026783799296165

[42] Isaksson, K., Hellgren, J. et al. (2002). Repeated Downsizing: Attitudes and Well-being for Surviving Personnel in a Swedish Retail Company. Health Effects of the New Labour Market. https://doi.org/10.1007/0-306-47181-7_8

[43] Quinlan, M., Mayhew, C., \& Bohle, P. (2005). The Global Expansion of Precarious Employment, Work Disorganization, and Consequences for Occupational Health: A Review of Recent Research. International Journal of Health Services, 31(2), 335-414. https://doi.org/10.2190/607H-TTV0-QCN6-YLT4

[44] Schaubroeck, J. (1991). Work Stress and Employee Health. Journal of Management, 17(2), 235-271. https://doi.org/10.1177/014920639101700202

\section{Contact information:}

Srđan VULANOVIĆ, PhD, Assistant Professor University of Novi Sad, Faculty of Technical Sciences, Trg Dositeja Obradovića 6, 21000 Novi Sad, Serbia E-mail: srdjanv@uns.ac.rs

Milan DELIĆ, PhD, Associate Professor (Corresponding author)

University of Novi Sad, Faculty of Technical Sciences Trg Dositeja Obradovića 6, 21000 Novi Sad, Serbia

E-mail: delic@uns.ac.rs

Ilija ĆOSIĆ, PhD, Emeritus Professor University of Novi Sad, Faculty of Technical Sciences, Trg Dositeja Obradovića 6, 21000 Novi Sad, Serbia

E-mail: ilijac@uns.ac.rs

Marina ŽIŽAKOV, MSc, Teaching Assistant University of Novi Sad, Faculty of Technical Sciences, Trg Dositeja Obradovića 6, 21000 Novi Sad, Serbia

E-mail: marinazizakov@uns.ac.rs

Stana VASIĆ, MSc, Teaching Associate University of Novi Sad, Faculty of Technical Sciences, Trg Dositeja Obradovića 6, 21000 Novi Sad, Serbia

E-mail: vasic.stana@uns.ac.rs 